\title{
Genetic Variation and Gains in Resistance of Strawberry to Colletotrichum gloeosporioides
}

\author{
L. F. Osorio, J. A. Pattison, N. A. Peres, and V. M. Whitaker
}

First, third, and fourth authors: University of Florida, Gulf Coast Research and Education Center, 14625 CR 672, Wimauma 33598; and second author: Department of Horticulture Science, North Carolina State University, Raleigh. Accepted for publication 21 August 2013.

\section{ABSTRACT}

Osorio, L. F., Pattison, J. A., Peres, N. A., and Whitaker, V. M. 2014. Genetic variation and gains in resistance of strawberry to Colletotrichum gloeosporioides. Phytopathology 104:67-74.

Anthracnose crown rot is an important disease of strawberry primarily caused by Colletotrichum gloeosporioides in Florida and North Carolina. Information on the magnitude of additive and nonadditive genetic variation is required to define breeding strategies and to estimate potential genetic gains. However, little is known about the genetic control of resistance and its utility in breeding. Our objectives were to obtain estimates of heritabilities and of components of genetic variances, genotypeenvironment interactions, and gains for resistance, and to examine the effects of locations and transplant types on the estimates. An incomplete diallel mating design generated 42 full-sib families, which were propagated in plugs from seed (seedling tests) and as bare-root runner plants (clonal tests) of different genotypes of the same families. Both seedlings and clones were inoculated with $C$. gloeosporioides under field condi- tions in North Carolina and Florida during the 2010-11 season. Narrowsense heritability $\left(h^{2}\right)$ and broad-sense heritability $\left(H^{2}\right)$ for both clones and seedlings were higher at the North Carolina location $\left(h^{2}=0.34\right.$ to 0.62 and $H^{2}=0.46$ to 0.85$)$ than at the Florida location $\left(h^{2}=0.16\right.$ to 0.22 and $H^{2}=0.37$ to 0.46 ). Likewise, the seedling tests showed higher genetic control than the clonal tests at both locations. Estimates of dominance variance were approximately one-third of the additive variance at North Carolina and were even larger at Florida. Epistasis was negative at both locations and assumed zero for heritability $\left(H^{2}\right)$ calculations. Genotypeenvironment interactions were different by transplant type, suggesting rank changes across locations. 'Pelican' was the most resistant parent at both locations, followed by 'NCH09-68' at the NC location and 'Winter Dawn' at the Florida location. Selection and deployment of the most resistant clone within each of the five best families is estimated to produce average genetic gains of 53.0 and $73.7 \%$ at the North Carolina and Florida locations, respectively.
Anthracnose diseases caused by Colletotrichum spp. are important in cultivated strawberry (Fragaria $\times$ ananassa Duchesne) worldwide. Colletotrichum fragariae A. N. Brooks, C. gloeosporioides (Penz.) Penz. \& Sacc. (teleomorph: Glomerella cingulata (Stoneman) Spauld. \& H. Schrenk), and C. acutatum J. H. Simmonds have been reported as causal agents, often producing similar symptoms and affecting foliage, stems, crowns, runners, flowers, and fruit $(10,18)$.

Anthracnose crown rot is caused by either $C$. fragariae or C. gloeosporioides, and disease is most prevalent under warm, humid environmental conditions such as those in the southeastern United States $(9,12,21)$. Under such environmental conditions, susceptible cultivars may become infected in either the nursery or fruiting field, which can result in reduced plant performance or plant death. Both species have been isolated from diseased strawberry crowns since the 1970s in Florida but C. gloeosporioides has been found more frequently (10). Later genetic studies examining diversity and population structure confirmed that C. gloeosporioides is, indeed, the primary species causing crown rot in Florida's production areas (21). C. acutatum is the primary cause of anthracnose fruit rot but this species occasionally infects crowns and roots. Crown and root infection of $C$. acutatum usually results in stunted plants rather than plant collapse or death (18).

Some outbreaks of C. gloeosporioides in Florida have caused entire fields to be lost (13), though plant losses of $<5 \%$ are more typical. The use of disease-free transplants is a recommended

Corresponding author: V. M. Whitaker; E-mail address: vwhitaker@ufl.edu

http://dx.doi.org/10.1094/PHYTO-02-13-0032-R

(c) 2014 The American Phytopathological Society control practice for anthracnose crown rot but disease incidence in transplants has historically been unpredictable across nursery sources and seasons. To complicate matters, inoculum is also spread from noncultivated hosts adjacent to strawberry fields throughout the strawberry-growing season. Isolates of C. gloeosporioides recovered from nine different host species adjacent to commercial fields were shown to be pathogenic on strawberry crowns (14,22). MacKenzie et al. (11) inoculated 11 C. gloeosporioides isolates to 10 different cultivars. Though they found significant differences in aggressiveness among isolates and significant differences in resistance among cultivars, they found no significant isolate-cultivar interactions.

Although some fungicides can help slow the spread of $C$. gloeosporioides inoculum within fields, no registered chemicals to date have shown the ability to slow disease progress in alreadyinfected crowns (13). Therefore, the deployment of genetic resistance is expected to be one of the most effective control measures. Strawberry breeding programs, including those at the University of Florida (UF), North Carolina State University (NCSU), and the United States Department of Agriculture-Agricultural Research Service (USDA-ARS) in Poplarville, MS, have developed cultivars and selections with resistance $(5,10,19)$. However, commercial cultivars used in the southeast are currently quite variable in their levels of resistance (12).

Several published studies on the inheritance of resistance to anthracnose diseases have studied the mode of gene action $(1,4,7)$ and the interaction of isolates of Colletotrichum spp. with cultivars $(4,11,12)$ but few reports have been published on the partitioning of the total genetic variance of resistance to diseases caused by Colletotrichum spp. $(7,9)$. This scarcity could be related to the lack of agreement in the mode of gene action because 
some authors have suggested a major gene model $(4,7)$ and others a quantitative genetic model $(1,9)$.

Previous experiments examining strawberry resistance to $C$. fragariae and $C$. acutatum used variable population sizes and gave contrasting results of estimates of additive and dominance variance (9). One experiment with a small population of six parents and nine full-sib families gave as a result an estimate of additive variance four times higher than the estimate of dominance variance and a very large narrow-sense heritability $\left(h^{2}=\right.$ 0.89 ). Another experiment with a large population of 40 parents and 87 full-sib families produced an estimate of dominance variance 10 times higher than the additive variance (9). An additional study, based on a fixed model, of a small population of six parents and 14 full-sib families reported specific combining ability (SCA) of resistance to $C$. acutatum larger than the estimate of general combining ability (GCA) (7).

Most notably, there are no published reports on the inheritance of resistance or the partitioning of genetic variance of resistance to $C$. gloeosporioides in strawberry that could inform breeding decisions. In addition, some knowledge of genotype-location interactions at the parental, full-sib family, and clonal cultivar levels would be important for public breeding programs in the southeastern United States that wish to move and deploy breeding material and cultivars across the region. This kind of information would also allow a determination of the potential genetic gains that can be achieved in a breeding program. The impact of the propagation method on both the incidence of disease and the stability of genetic effects has not been determined. Because both plug (containerized) and bare-root transplants are utilized in the commercial industry and in breeding programs, it is advisable to examine resistance using both types.

The primary goals of this study were to (i) obtain estimates of heritabilities for resistance to $C$. gloeosporioides at two locations in the southeastern United States; (ii) examine genotype-environment interactions among parents, full-sib families, and clones; (iii) estimate genetic gains from family selection and clone-withinfamily selection; and (iv) examine the influence of transplant type (seedlings versus runner plants or clones) on the estimates.

\section{MATERIALS AND METHODS}

Mating and field designs. In total, 42 full-sib families (54 total crosses made, including reciprocals) were generated from an unbalanced incomplete diallel design among 11 parents (Table 1).
The mating design is best described as method III, where only one set of the F1s and reciprocals are crossed, selfs are excluded, and the genotypes are assumed to be a random sample of the population (8). The diallel was incomplete due to the lack of representation of some crosses in the design, which was the result of insufficient parent plants to make all crosses in some cases and variable seed germination in other cases. The design was unbalanced due to differing numbers of individuals tested from each cross. The parental population included commercial cultivars as well as two advanced selections from NCSU to represent a wide range of resistance to $C$. acutatum, C. fragariae (19), and $C$. gloeosporioides $(11,12)$.

Controlled crosses were conducted at NCSU in early 2010. A random subset of seed was germinated at the Gulf Coast Research and Education Center (GCREC) of the UF at Wimauma in April 2010. The seedlings were transported to the UF breeding program's summer nursery in Monte Vista, CO where they were clonally propagated via runners, generating four bare-root plants from each seedling. Two runner plants were established at the GCREC (latitude $27^{\circ} 45^{\prime} 36^{\prime \prime} \mathrm{N}$, longitude $82^{\circ} 13^{\prime} 45^{\prime \prime} \mathrm{W}$ ) on 4 October 2010 and two runner plants were established at the Horticultural Crops Research Station in Castle Hayne, NC (latitude $34^{\circ} 19^{\prime} 16^{\prime \prime} \mathrm{N}$, longitude $\left.77^{\circ} 54^{\prime} 58^{\prime \prime} \mathrm{W}\right)$ on 14 October 2010. An average of 30 genotypes (from here on referred to as "clones" due to their clonal propagation as runner plants) per full-sib family were arranged in a randomized complete block design (RCBD) with two replications at each site and single-plant plots as the unit of replication. The plants were arranged in the fields using four raised beds per replication in Florida and five raised beds per replication in North Carolina.

In June 2010, an additional set of seed from the same full-sib families was germinated and transplanted into 50-cell plug trays at NCSU beginning on 9 July. Thirty mature seedling plugs per family were planted on 4 October in Florida and 14 October in North Carolina adjacent to the clonal trials. An RCBD with eight raised beds (replications), single-plant plots, and three to four plants per family per replication was established in Florida, and a similar design with five replications and four to six seedlings per replication was planted in North Carolina. The design was unbalanced because the families and the number of genotypes per family and test were somewhat different across sites. A summary of the design is presented in Table 2.

Inoculation and data collection. The inoculum was prepared from 5- to 7-day-old cultures of C. gloeosporioides isolate 07-120

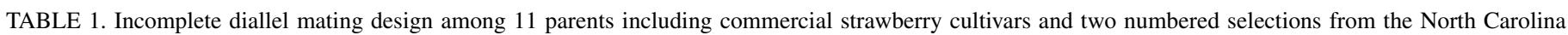
State University strawberry breeding program ${ }^{\mathrm{a}}$

\begin{tabular}{|c|c|c|c|c|c|c|c|c|c|c|c|}
\hline Parent & $\mathrm{AP}$ & $\mathrm{CR}$ & SF & GA & N7 & N8 & $\mathrm{PE}$ & $\mathrm{SC}$ & $\mathrm{TI}$ & TR & WD \\
\hline 'Apollo' (AP) & $\ldots$ & 89 & 92 & 61 & - & - & 89 & 92 & 88 & 88 & 90 \\
\hline 'Camino Real' (CR) & - & $\ldots$ & 86 & 91 & - & - & - & 60 & 93 & 90 & 87 \\
\hline 'Strawberry Festival' (SF) & - & - & $\ldots$ & 90 & - & - & - & 58 & 90 & 44 & 42 \\
\hline 'Galletta' (GA) & - & - & 59 & $\ldots$ & - & - & - & 90 & 60 & - & - \\
\hline NCH 09-67 (N7) & - & 91 & - & - & $\ldots$ & - & - & 61 & 51 & - & 88 \\
\hline NCH 09-68 (N8) & - & 89 & 30 & - & - & $\ldots$ & - & 31 & 61 & - & 90 \\
\hline 'Pelican' (PE) & - & 90 & 60 & - & - & - & $\ldots$ & 90 & 90 & - & - \\
\hline 'Sweet Charlie' (SC) & - & 61 & 32 & 30 & - & - & 30 & $\ldots$ & 90 & 5 & - \\
\hline 'Tillamook' (TI) & - & 61 & 60 & 30 & - & - & - & 30 & $\ldots$ & - & 91 \\
\hline 'Treasure' (TR) & - & 54 & 30 & 71 & - & - & - & 13 & 89 & $\ldots$ & - \\
\hline 'Winter Dawn' (WD) & - & - & - & 60 & - & - & - & 59 & - & 30 & $\ldots$ \\
\hline
\end{tabular}

a Number of tested genotypes per full-sib family.

TABLE 2. Summary of field inoculation experiments by location and transplant type (seedlings versus bare-root runner plants or clones)

\begin{tabular}{|c|c|c|c|c|c|c|}
\hline Location & Test & Full-sib families & Crosses & Genotypes & Runners, genotype & Observations \\
\hline \multirow[t]{2}{*}{ Wimauma, FL } & Clonal & 42 & 52 & 1,419 & 2 & 2,778 \\
\hline & Seedling & 37 & 37 & 1,060 & - & 1,076 \\
\hline \multirow[t]{2}{*}{ Castle Hayne, NC } & Clonal & 42 & 51 & 1,366 & 2 & 2,611 \\
\hline & Seedling & 31 & 35 & 1,027 & - & 1,027 \\
\hline
\end{tabular}


(isolated in 2007 from 'Treasure') grown on potato dextrose agar under continuous fluorescent light at $24^{\circ} \mathrm{C}$. Conidial suspensions used for inoculations were prepared in sterile deionized water, filtered through four layers of cheesecloth, and diluted to $4 \times 10^{5}$ conidia/ml. Inoculations were performed by spraying $2 \mathrm{ml}$ of the conidial suspension directly into the crown of each plant with a backpack sprayer on 18 October 2010 in Florida and on 8 November 2010 and 9 March 2011 in North Carolina. Due to slow symptom development in North Carolina during the fall and winter, the second inoculation was performed to assure the presence of inoculum during more conducive temperatures.

Disease symptoms were recorded on an individual-plant basis every 2 weeks between 2 November 2010 and 5 April 2011 in Florida and weekly from 4 May 2011 to 7 June 2011 in North Carolina. Crown rot was assessed using different scales in the breeding programs at NCSU and at the UF due to the different presentations of disease systems in the two locations. In Florida, disease resistance was scored on a binomial scale assigning zero (0) to disease-free plants and one (1) to plants with $>80 \%$ of the plant collapsed. In North Carolina, a 0 to 5 scale was used in which $0=$ no symptoms; $1=$ initial signs of disease, mainly initial wilting of older leaves; $2<50 \%$ wilt, $3=>50 \%$ wilt; $4=>75 \%$ wilt; and $5=$ complete collapse (death).

Statistical models. Due to the variable environmental conditions during the strawberry season at the two locations, an incidence rate of 73 to $76 \%$ obtained in the last measurement of the clonal and seedling tests in North Carolina was used for the analyses. A similar incidence rate at the 6th and 18th measurement dates was used for clones (75\%) and seedlings (75\%), respectively, in Florida (Fig. 1).

Single-site analysis by transplant type, clones, and seedlings, were conducted using ASReml software (VSN International Ltd., UK). This software allowed the estimation of variance components by fitting linear mixed models using the average information REML algorithm. ASReml also fits generalized linear mixed models (GLMM) and estimates variance components by using the technique called penalized quasi-likelihood (PQL) (6).
All analyses were based on a parental model with pedigree (16) tracing back 20 generations of improvement. Preliminary statistical analyses, including reciprocal effects, indicated that the variance component for this effect was close to zero and not significant for any of the analyses. Therefore, the reciprocal effect term was dropped from the models and all further analyses considered crosses in one direction and their reciprocals as the same full-sib families.

Single-site analyses at Florida, which were based on a binary scale (0 to 1$)$, were analyzed using GLMM. The probability of disease of individual plants $(\pi)$ in the clonal test was fitted by a GLMM using a logit link function, $\eta=\log [\pi /(1-\pi)]$, to estimate variance components. The link function $(\eta)$ relates the binary observations in $y$ to the linear predictor of fixed and random effects, such that (20):

$$
y=\eta+e=X \beta+Z_{1} d+Z_{2} a+Z_{3} f+Z_{4} c+e
$$

where $y$ is the vector of observations, $\beta$ is the vector of fixed effects (i.e., mean, replications), $\boldsymbol{X}$ is the design matrix relating the fixed effects to the observations in $y, \boldsymbol{d}$ is the vector of beds within replication effects, $\boldsymbol{a}$ is a vector of random parental effects, $\boldsymbol{f}$ is a vector of random family effects, $\boldsymbol{c}$ is a vector of random clone within family effects, and $\boldsymbol{e}$ is the vector of random residuals effects. $\boldsymbol{Z}_{\mathbf{1}}$ to $\boldsymbol{Z}_{\mathbf{4}}$ are known design matrices relating the observations in $y$ to effects in $\boldsymbol{d}, \boldsymbol{a}, \boldsymbol{f}$, and $\boldsymbol{c}$, respectively.

The distribution for the random effects in vectors $\boldsymbol{d}, \boldsymbol{a}, \boldsymbol{f}$, and $\boldsymbol{c}$ were expressed $\left[d \approx N\left(0, I_{b} \sigma_{b}^{2}\right), a \approx N\left(0, A \sigma_{g c a}^{2}\right), f \approx N\left(0, I_{f} \sigma_{s c a}^{2}\right)\right.$, $\left.c \approx N\left(0, I_{c} \sigma_{c l(f)}^{2}\right)\right]$ where $\sigma_{b}^{2}$ is the bed within replication effect, $A$ is the numerator relationship matrix among parents and $\sigma_{g c a}^{2}$ is the female and male GCA, $\sigma_{s c a}^{2}$ is the SCA, $\sigma_{c l(f)}^{2}$ is the clone within full-sib family variance, and $\sigma_{e}^{2}$ is the error variance, which is fixed in GLMM to a value of 3.29 (6). $I_{b}, I_{f}$, and $I_{c}$ are identity matrices of order equal to the number of beds within replication, number of families, and number of clones, respectively. Random effects were assumed to be uncorrelated among themselves and uncorrelated with residual effects.

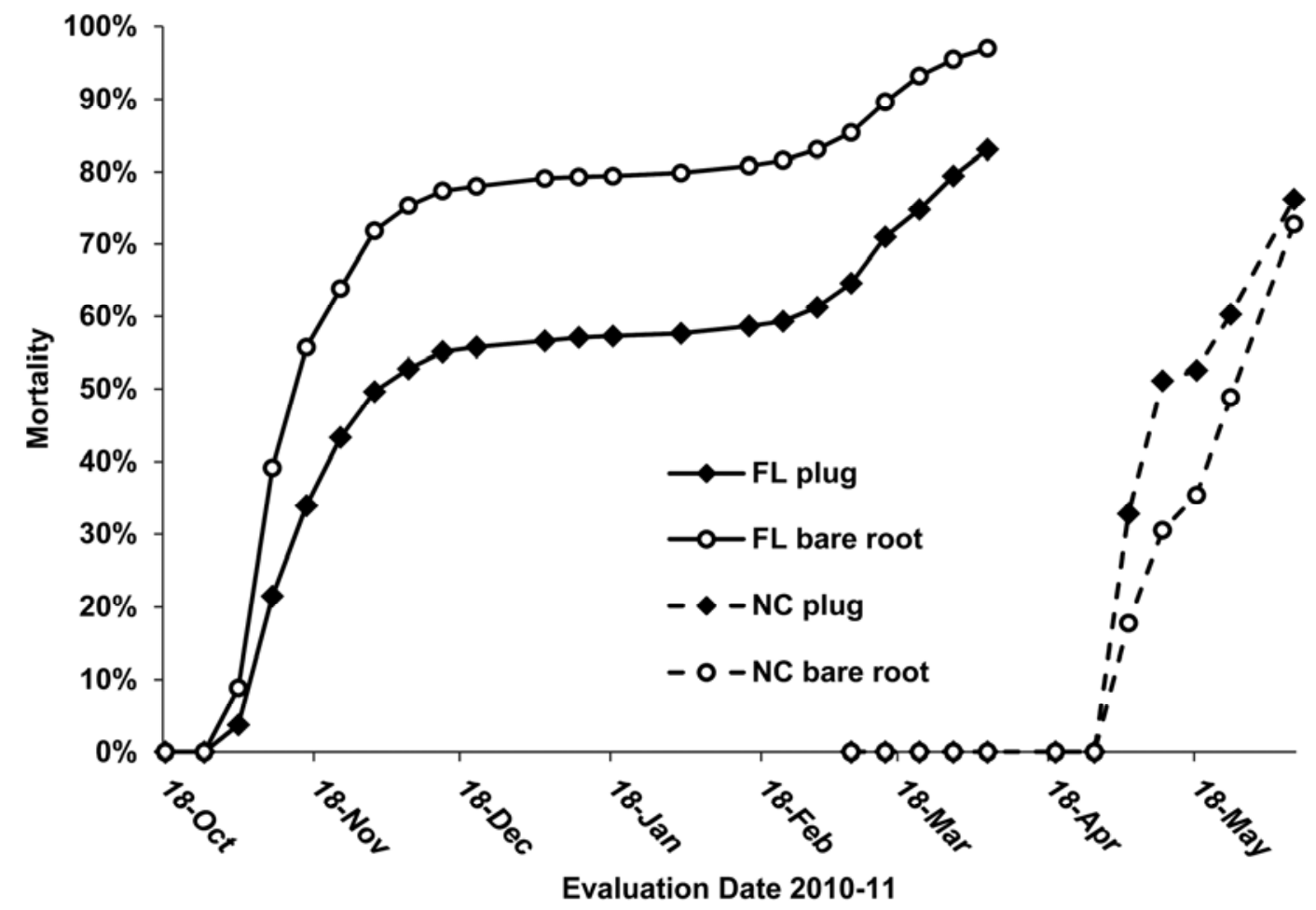

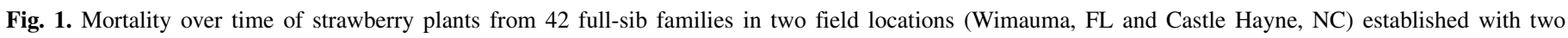
transplant types (plug plants and bare-root plants or clones) after inoculation with Colletotrichum gloeosporioides. 
The seedling test at Florida was analyzed similarly to model 1, except that the bed within replication and the clone effect were removed:

$$
y=\eta+e=X \beta+Z_{1} a+Z_{2} f+e
$$

The seedling test and the clonal test in North Carolina measured in the multinomial scale ( 0 to 5$)$ were analyzed using GLMM with both logit and probit link functions but, in all cases, the models showed under-dispersion, with heterogeneity factors $\leq 0.53$, indicating a poor goodness of fit of the data to the models. Moreover, the distribution of residuals was better for a model on the original scale than on either the GLMM models or different models with data transformations. Therefore, the analyses for North Carolina were performed using linear mixed models and considering the 0 to 5 scale as normally distributed.

The clonal test and the seedling test at North Carolina were analyzed according to the following models, respectively:

$$
\begin{gathered}
y=X \beta+Z_{1} d+Z_{2} a+Z_{3} f+Z_{4} c+e \\
y=X \beta+Z_{1} a+Z_{2} f+e
\end{gathered}
$$

All vectors, design matrices, and random variance components have been previously defined.

Genetic variation. The variance components derived from the statistical model are related to the causal additive $\left(\sigma_{v a}^{2}\right)$, dominance $\left(\sigma_{v d}^{2}\right)$, and epistatic genetic variances $\left(\sigma_{v i}^{2}\right)$ for the clonal analyses (17) by

$$
\sigma_{g c a}^{2}=\frac{1}{4} \sigma_{v a}^{2} ; \sigma_{s c a}^{2}=\frac{1}{4} \sigma_{v d}^{2} \text { and } \sigma_{c l(f)}^{2}=2 \sigma_{g c a}^{2}+3 \sigma_{s c a}^{2}+\sigma_{v i}^{2}
$$

where $\sigma_{v i}^{2}$ is an estimate of the larger fraction of epistatic variance contained in clones within families. Based on these relationships, the epistatic variance is $\sigma_{v i}^{2}=\sigma_{c l(f)}^{2}-2 \sigma_{g c a}^{2}-3 \sigma_{s c a}^{2}$ and the total genetic variance is given by $\sigma_{G}^{2}=\sigma_{v a}^{2}+\sigma_{v d}^{2}+\sigma_{v i}^{2}$. For the seedling tests, no estimate of epistatic variance is possible and is assumed absent. Estimates of $h^{2}$ and broad-sense heritability $\left(H^{2}\right)$ were calculated as the ratio of additive variance $\left(\sigma_{v a}^{2}\right)$ and total genetic variance $\left(\sigma_{G}^{2}\right)$ to the phenotypic variance $\left(\sigma_{P}^{2}\right)$. Estimates of the clonal phenotypic variance and of the seedling phenotypic variance were computed as $\sigma_{P}^{2}=2 \sigma_{g c a}^{2}+\sigma_{s c a}^{2}+\sigma_{c l(f)}^{2}+\sigma_{e}^{2}$ and $\sigma_{P_{S}}^{2}=2 \sigma_{g c a}^{2}+\sigma_{s c a}^{2}+\sigma_{e}^{2}$, respectively. Similarly, estimates of the proportion of the dominance variance $\left(D^{2}\right)$ and epistatic variance $\left(I^{2}\right)$ from the seedling tests and clonal tests were generated as the ratio of the estimate to the corresponding phenotypic variance.

The genetic correlation of the same trait between two different environments, the type B genetic correlation, has been used to estimate the magnitude of genotype-environment interaction $(\mathrm{G} \times$ E) (3). The type B genetic correlation was estimated for both the clonal and seedling tests as the Pearson correlation of breeding values of the parents, the correlation of full-sib family breeding values, and the correlation of clonal values between North Carolina and Florida. Full-sib family breeding values were calculated by adding the GCA of the parents to the full-sib family SCA variance. Clonal genetic values were calculated by adding the GCA of the parents, the full-sib family SCA variance, and the clone-within-family variance $(2)$.

Type B genetic correlations $\left(r_{\mathrm{B}}\right)$ were 0 to 1 , with values closer to 1 indicating a small $\mathrm{G} \times \mathrm{E}$ effect. In general, $r_{\mathrm{B}}$ values $>0.67$ suggest a small $\mathrm{G} \times \mathrm{E}$ effect with few or no changes in the rankings of genotypes (15).

Genetic gains. Gains from all parents, full-sib families, and clones within full-sib families were estimated from each test and site using the breeding values or clonal values expressed as percent gains over the mean of the trait, as previously reported in other studies (2). An average genetic gain was estimated by simulating the selection and deployment of the most resistant clone within each of the most resistant five full-sib families at each site.

\section{RESULTS}

In total, 2,087 seedling genotypes (propagated as plug plants from seed) and 1,490 different clonal genotypes (runner plants) from 42 full-sib families were evaluated for their field resistance to C. gloeosporioides at Wimauma, FL and Castle Hayne, NC (Table 2). Some reciprocal crosses were included in the diallel design (Table 2); however, they were not significant when tested by a one-tailed likelihood ratio test with $\chi_{0.05}^{2}(6)$. Therefore, no maternal effects were detected, and crosses in both directions were considered as the same full-sib family in all subsequent analyses.

The pattern of mortality over time was distinctly different across locations for both transplant types, reflecting wide differences in environmental conditions over the time of evaluation (Fig. 1). Mortality reached the $75 \%$ incidence level in the clonal trial in

\begin{tabular}{|c|c|c|c|c|c|c|c|c|}
\hline \multirow[b]{2}{*}{$\mathrm{VC}^{\mathrm{a}}$} & \multicolumn{4}{|c|}{ Castle Hayne, NC } & \multicolumn{4}{|c|}{ Wimauma, FL ${ }^{b}$} \\
\hline & Seedling test & $\mathrm{VC}(\%)^{\mathrm{c}}$ & Clonal test & $\mathrm{VC}(\%)$ & Seedling test & $\mathrm{VC}(\%)$ & Clonal test & $\mathrm{VC}(\%)$ \\
\hline$\sigma_{b}^{2}$ & - & - & 0.012 & 0.9 & - & - & 0.0 & 0.0 \\
\hline $2 \sigma_{g c a}^{2}$ & 0.474 & 31.2 & 0.228 & 17.2 & 0.428 & 10.8 & 0.336 & 7.9 \\
\hline$\sigma_{s c a}^{2}$ & 0.085 & 5.6 & 0.040 & 3.0 & 0.246 & 6.2 & 0.225 & 5.3 \\
\hline$\sigma_{c l(f)}^{2}$ & - & - & 0.267 & 20.1 & - & - & 0.398 & 9.4 \\
\hline$\sigma_{P}^{2}$ & 0.962 & 63.2 & 0.796 & 59.8 & $3.290^{\mathrm{d}}$ & 83.0 & $3.290^{\mathrm{d}}$ & 77.4 \\
\hline$\sigma_{e}^{2}$ & 1.521 & - & 1.332 & - & 3.964 & - & 4.249 & - \\
\hline$h^{2}$ & $0.62 \pm 0.23^{\mathrm{e}}$ & - & $0.34 \pm 0.14$ & - & $0.22 \pm 0.13$ & - & $0.16 \pm 0.09$ & - \\
\hline$H^{2}$ & $0.85 \pm 0.20$ & - & $0.46 \pm 0.14$ & - & $0.46 \pm 0.15$ & - & $0.37 \pm 0.10$ & - \\
\hline$D^{2}$ & $0.22 \pm 0.10$ & - & $0.12 \pm 0.05$ & - & $0.25 \pm 0.13$ & - & $0.21 \pm 0.08$ & - \\
\hline$I^{2}$ & 0.0 & - & $-0.06 \pm 0.09^{f}$ & - & 0.0 & - & $-0.14 \pm 0.07^{f}$ & - \\
\hline
\end{tabular}
Florida by 7 December. Conversely, the clonal trial in North Caro-

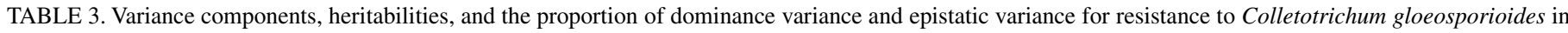
strawberry evaluated at two locations using seedling plugs and bare-root runner plants (clones)

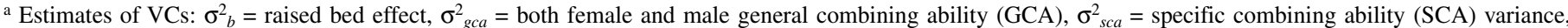
$\sigma_{c l(f)}^{2}=$ clone within family variance, $\sigma_{e}^{2}=$ residual error, $\sigma_{P}^{2}=$ phenotypic variance, $h^{2}=$ narrow-sense heritability, $H^{2}=$ broad-sense heritability, $D^{2}=$ proportion of dominance variance, and $I^{2}=$ proportion of epistatic variance.

b Variance components (VCs) and parameter estimates in Florida are in the underlying distribution (logit).

c Percentage of total variance accounted for by each variance component.

${ }^{\mathrm{d}}$ Residual error in the generalized linear mixed models at Florida is fixed to 3.290 (6).

e Standard errors of parameter estimates.

f Epistasis was negative in the clonal tests and assumed zero for the purposes of heritability $\left(H^{2}\right)$ calculations. 
lina did not reach this incidence level until 7 June. Disease progress was more rapid in the clonal trial than in the seedling trial in Florida but the opposite occurred in North Carolina (Fig. 1).

Variance components from North Carolina are reported in the normal scale and those from Florida are in the underlying scale (transformed from the 0 to 1 scale); however, they can be compared as proportions of the total variance in the trials (Table 3). The $h^{2}$ and $H^{2}$ were higher in North Carolina than in Florida (Table 3). Likewise, the seedling tests showed a higher genetic control than the clonal tests at both locations. GCA variance ranged widely, from $31.2 \%$ of the total variance in the seedling test in North Carolina to $7.9 \%$ of the total variance in the clonal test in Florida. GCA variance was approximately six times larger than SCA variance in both tests in North Carolina but less than double the SCA in the tests in Florida. The proportion of dominance variance $\left(D^{2}\right)$ was almost the same across locations, except for the clonal test at North Carolina, and the epistatic proportion $\left(I^{2}\right)$ in the clonal studies was negative (Table 3 ). For the clonal tests, the percentage of the clone within full-sib family variance component was slightly larger than the parental variance at both locations. The unexplained residual variance of the singlesite tests accounted for 60 to $83 \%$ of the total variance, with lower residual variances at the North Carolina location (Table 3).

The $G \times E$ interactions of the parental and full-sib family breeding values were low in the clonal tests, as shown by type B correlations $>0.75$, but were higher for the additive and full-sib family effects of the seedling tests (Table 4). At the clonal level, the $\mathrm{G} \times \mathrm{E}$ was moderate $(0.61)$.

Genetic gains $(\%)$ for parents by trial and location are presented in Table 5. 'Pelican' and 'NCH09-68' conferred the greatest resistance to $C$. gloeosporioides across all tests, followed by Treasure and 'Winter Dawn'. Pelican and NCH09-68 were the best parents for resistance in North Carolina, and Pelican and Winter Dawn were the best parents in Florida. 'NCH09-67', an advanced selection from the strawberry breeding program at NCSU and full sib to NCH09-68, and 'Sweet Charlie' and 'Strawberry Festival', two cultivars released by the strawberry breeding

TABLE 4. Genotype-environment interaction of parental breeding values, full-sib family breeding values, and clonal values for Colletotrichum gloeosporioides between seedling and clonal tests in North Carolina and Florida

\begin{tabular}{lcc}
\hline Genetic correlations $^{\mathrm{a}}$ & Seedling tests & Clonal tests \\
\hline$\hat{r}_{\text {add }}$ & $0.65(0.0307)$ & $0.79(0.0041)$ \\
$\hat{r}_{f s}$ & $0.54(0.0021)$ & $0.75(0.0001)$ \\
$\hat{r}_{\text {clone }}$ & - & $0.61(0.0001)$ \\
\hline
\end{tabular}

a Estimates: $\hat{r}_{a d d}=$ type B genetic correlation of additive effects, $\hat{r}_{f s}=$ type B genetic correlation of full-sib families, and $\hat{r}_{\text {clone }}=$ type B genetic correlation of clones. Significance values of the correlations are within parentheses. program at the UF GCREC, conferred variable levels of resistance. 'Tillamook', a USDA-ARS release in the Pacific Northwest, and 'Camino Real', developed at the University of CaliforniaDavis, were the third and second most susceptible parents, respectively. The most susceptible parent on average was 'Galletta', an NCSU release, which conferred an average gain of $-9.0 \%$ across sites and tests.

The top five full-sib families in terms of genetic gains (\%) in each trial included either Pelican or NCH09-68 as a parent, except for the cross Camino Real $\times$ Strawberry Festival in the clonal test in Florida (Figs. 2 and 3). Full-sib family genetic gains for the five best families in North Carolina were 7.1 to $22.7 \%$, and 23.5 to $40.4 \%$ at Florida. The average of best family gains was higher in North Carolina compared with Florida. Average genetic gains (\%) of the best clones (the best clone from each of the five best full-sib families) resulted in genetic gains in resistance to $C$. gloeosporioides of 53.0 and $73.5 \%$ in North Carolina and Florida, respectively.

\section{DISCUSSION}

In this study, heritability estimates revealed that progress can be made in breeding for resistance to $C$. gloeosporioides in strawberry in both the Florida and North Carolina locations but the rate of progress may be influenced by location and transplant type. Practically, our results suggest a large potential to increase genetic gains by exploiting nonadditive variance through clonal propagation when examining single locations, especially in Florida. The clonal tests showed a low $\mathrm{G} \times \mathrm{E}$ interaction of additive and full-sib family breeding values but a moderate $\mathrm{G} \times \mathrm{E}$ interaction of clonal values, indicating cultivar rank changes between both locations. Full-sib family selection plus clone-within-family selection indicated a sizeable potential to increase genetic gains in resistance, up to 53 and $74 \%$ in at North Carolina and Florida respectively.

The lack of significance of the reciprocal crosses in these tests implied that there were no maternal effects associated with the resistance to $C$. gloeosporioides and that a similar response would be obtained from crosses in both directions. Except for the seedling test at North Carolina, $H^{2}$ estimates in this study were lower than those previously reported in a large population to examine resistance of strawberry to $C$. fragariae and $C$. acutatum (9). The $h^{2}$ estimates from both transplant types were lower at the Florida location and higher in the seedling test in North Carolina compared with the previous study (9). This is not a surprising result because estimation of heritabilities and genetic correlations are unique to environments, inoculation and rating methods, and germplasm, and should be estimated under the unique conditions of each breeding program.

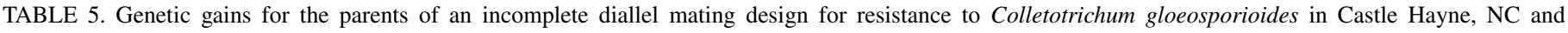
Wimauma, FL established from seedling plugs and bare-root runner plants (clones) ${ }^{\mathrm{a}}$

\begin{tabular}{|c|c|c|c|c|c|c|c|c|}
\hline \multirow[b]{3}{*}{ Parents } & \multicolumn{3}{|c|}{ Seedling tests } & \multicolumn{3}{|c|}{ Clonal tests } & \multirow[b]{3}{*}{ Average gain (\%) } & \multirow[b]{3}{*}{ Overall rank } \\
\hline & \multicolumn{2}{|c|}{ Genetic gain $(\%)$} & \multirow[b]{2}{*}{ Rank } & \multicolumn{2}{|c|}{ Genetic gain $(\%)$} & \multirow[b]{2}{*}{ Rank } & & \\
\hline & North Carolina & Florida & & North Carolina & Florida & & & \\
\hline 'Pelican' & 16.1 & 26.2 & 1 & 16.3 & 19.2 & 1 & 19.5 & 1 \\
\hline NCH 09-68 & 18.5 & -0.3 & 2 & 9.0 & 1.2 & 2 & 7.1 & 2 \\
\hline 'Treasure' & 9.2 & 2.1 & 3 & 4.6 & 5.4 & 3 & 5.3 & 3 \\
\hline 'Winter Dawn' & 1.9 & 3.7 & 4 & 1.7 & 5.3 & 4 & 3.2 & 4 \\
\hline 'Sweet Charlie' & -0.9 & 1.3 & 5 & -2.5 & -1.2 & 7 & -0.8 & 5 \\
\hline 'Strawberry Festival' & -4.5 & -1.9 & 6 & -6.9 & 4.1 & 6 & -2.3 & 6 \\
\hline NCH 09-67 & -3.8 & -10.1 & 9 & 0.9 & -3.4 & 5 & -4.1 & 7 \\
\hline 'Apollo' & -8.6 & -0.4 & 7 & -6.3 & -6.7 & 9 & -5.5 & 8 \\
\hline 'Tillamook' & -8.8 & -1.1 & 8 & -7.0 & -6.8 & 10 & -5.9 & 9 \\
\hline 'Camino Real' & -9.0 & -11.3 & 11 & -5.5 & -0.8 & 8 & -6.7 & 10 \\
\hline 'Galletta' & -10.3 & -5.0 & 10 & -8.5 & -12.3 & 11 & -9.0 & 11 \\
\hline
\end{tabular}

a Parental rankings by location for seedling and clonal tests and the overall ranking are based on average genetic gains. 
Even though the proportion of dominance variance $\left(D^{2}\right)$ was high in magnitude and positive across location and transplant type, its contribution to the $H^{2}$ differed. In the clonal tests, the dominance variance had a lower effect in North Carolina than in Florida but, in the seedling trials, the proportion of dominance variance was similar. A previous study conducted in Castle Hayne, $\mathrm{NC}$ concluded that nonadditive effects were more important than additive effects in resistance to $C$. acutatum (7). Likewise, high estimates of dominance variance were found in a large-population experiment for strawberry resistance to $C$. fragariae and $C$. acu-

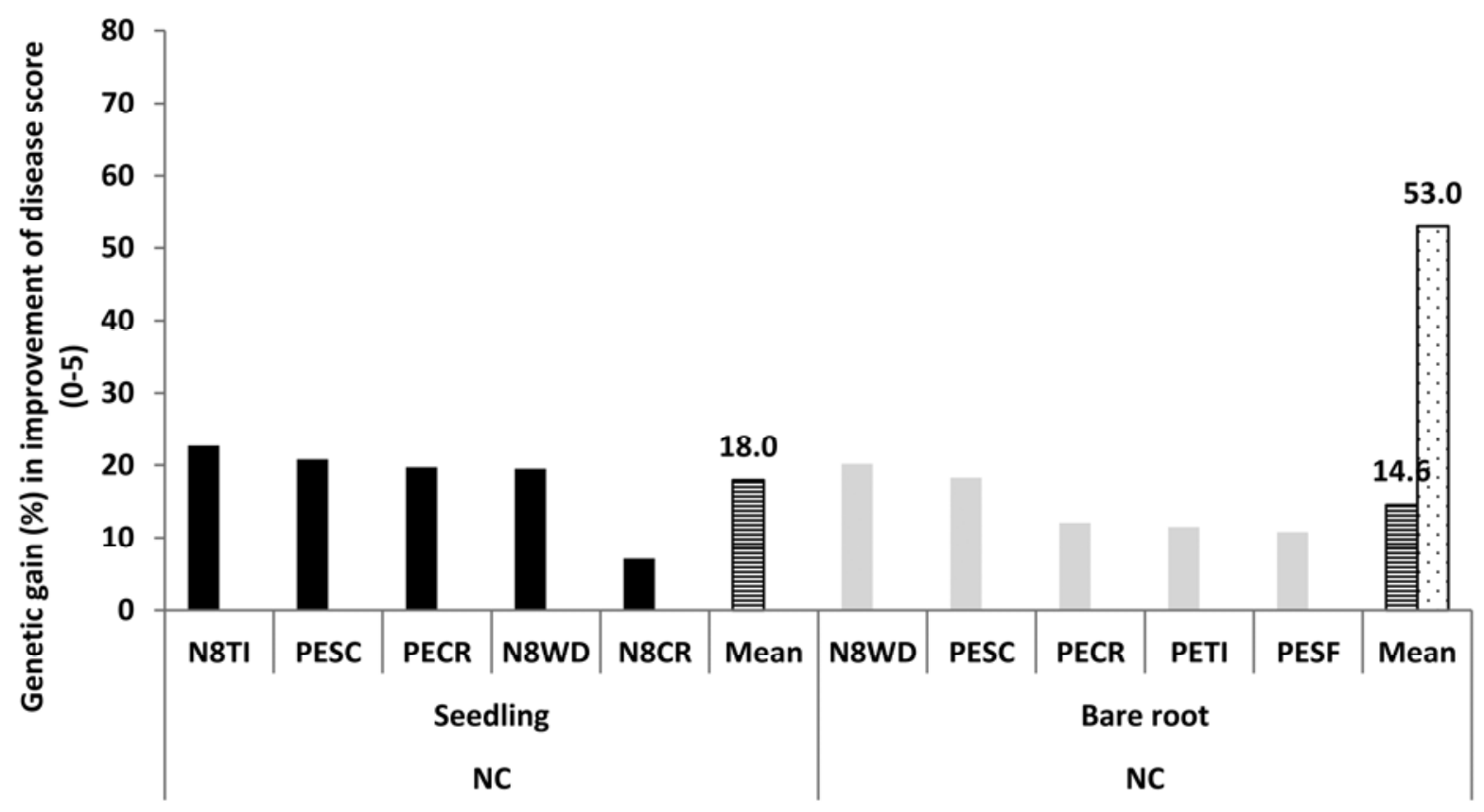

most Resistant Families $\square$ Mean of Most Resistant Clones

Fig. 2. Genetic gains for resistance to Colletotrichum gloeosporioides by transplant type (plug plants and bare-root plants or clones) at Castle Hayne, NC. Genetic gains are expressed as the percentage improvement in the disease score (0 to 5) over the population mean. The most resistant five full-sib families from each trial and their mean are shown, as well as the mean of the most resistant five clones (one from each of the most resistant five full-sib families). The family is indicated by four letters, the first two for the female parent and the last two for the male parent (AP = 'Apollo', CR = 'Camino Real', SF $=$ 'Strawberry Festival', GA = 'Galletta', NC7 = NCH 09-67, NC8 = NCH09-68, PE = 'Pelican', SC = 'Sweet Charlie', TI = 'Tillamook', TR = 'Treasure', and WD = 'Winter Dawn').

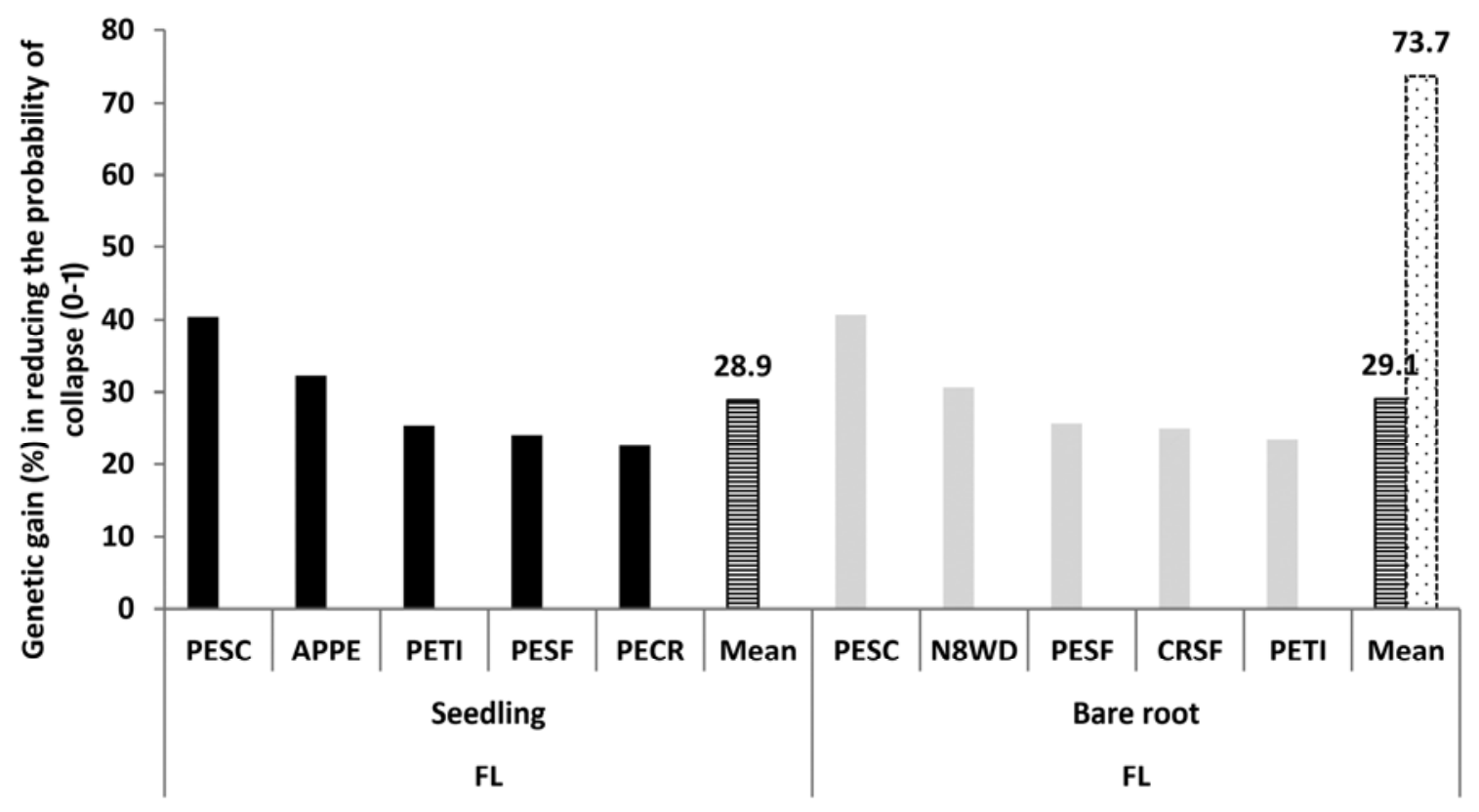

Most Resistant Families Mean of Most Restant Clones

Fig. 3. Genetic gains for resistance to Colletotrichum gloeosporioides by transplant type (plug plants and bare-root plants or clones) at Wimauma, FL. Genetic gains are expressed as a reduction (\%) in the probability of plant collapse over the population mean. The most resistant five full-sib families from each trial and their mean are shown, as well as the mean of the most resistant five clones (one from each of the most resistant five full-sib families). The family is indicated by four letters, the first two for the female parent and the last two for the male parent (AP = 'Apollo', CR = 'Camino Real', SF = 'Strawberry Festival', GA = 'Galletta', NC7 = NCH 09-67, NC8 = NCH09-68, PE = 'Pelican', SC = 'Sweet Charlie', TI = 'Tillamook', TR = 'Treasure', and WD = 'Winter Dawn' ). 
tatum (9). One advantage of controlled pollination combined with clonal testing is that the within-family variance can be partitioned into variances among and within clones, allowing estimation of epistasis. Earlier reports of epistatic effects for resistance to Colletotrichum spp. have accounted for 35 to $38 \%$ of the total genetic variance in females and males, respectively (9). In the present study, epistasis is unknown in seedling trials and must be assumed to be zero. In the clonal trials, epistasis was negative and was assumed to be zero for the purpose of calculating $H^{2}$, an assumption that is common in other studies (2). Negative estimates of epistasis may indicate insufficient variance among clones within families to account for additive and dominance effects. This could possibly be remedied in future studies by testing more clonal replicates per individual.

Greater heritabilities in the seedling tests compared with the single clonal tests were unexpected and might be related to an effect of the propagation system used for seedlings (plug transplants) and clones (bare-root transplants). It is possible that the plant size and root systems of seedlings might be more uniform, allowing a better expression of family differences. This could result from the seedlings growing in a greenhouse under the same environmental conditions prior to field planting, in contrast to the clones growing in an open-field nursery. It is also possible that the plug transplants established more quickly prior to inoculation due to an intact root system, which allowed the expression of genes for tolerance or resistance that differ across growth stages. A similar phenomenon could help explain the higher heritabilities in the North Carolina location compared with Florida. Due to less favorable conditions for disease development in the weeks after the November inoculation in North Carolina, the plants may have been more mature by the time disease began to develop, allowing expression of genes for tolerance or resistance that were not expressed in Florida. Indeed, there was a greater resistance observed in North Carolina than in Florida. By the time the average incidence of mortality of clones reached $\approx 75 \%$ in each location, full-sib family means were 22 to $94 \%$ mortality in North Carolina and 41 to $100 \%$ mortality in Florida.

The large type $\mathrm{B}$ genetic correlations at the parental and full-sib family level in the clonal tests revealed a low $\mathrm{G} \times \mathrm{E}$ interaction and suggest that there should be few rank changes in disease resistance across locations. Therefore, a resistant parent or full-sib family at one site should also be relatively resistant at the other. In contrast, the moderate $\mathrm{G} \times \mathrm{E}$ interaction observed at the clonal level points out that caution should be taken when cultivars are moved and deployed between regions with contrasting environments. For a strawberry breeding program oriented to testing and deploying genetic material in both sites, gains may come primarily through recurrent selection and less so from clonal deployment.

Efforts to develop germplasm with resistance to various Colletotrichum spp. in southern states have been in place for more than four decades (10). The high resistance of Pelican to C. acutatum, C. fragariae, and C. gloeosporioides has been previously reported $(11,18)$. The results confirm the singular importance of this clone by ranking it as the parent most resistant to C. gloeosporioides at both locations. This study also corroborates the resistance to crown rot of Treasure, as previously shown by MacKenzie et al. (12). All parents originating from Florida (Winter Dawn, Strawberry Festival, and Sweet Charlie) exhibit some level of disease resistance in Florida, apparently due to selection pressure applied during the testing phases because C. gloeosporioides is prevalent on native plants near field-testing locations (14). The parental performance of NCH09-68 at the North Carolina location suggests that this genotype will be useful in breeding for increased resistance to C. gloeosporioides. However, most of the genetic gains for this genotype were attributed to that location. NCH09-68 originated from a cross between two NCSU genotypes with diverse genetic backgrounds. Interestingly, a wild clone of
F. virginana subsp. grayana (NC 95-19-1, PI 612486) collected from Mississippi and observed to be immune to crown rot, is a grandparent of NCH09-68 (N. A. Peres, unpublished data).

Regarding the comparison of genetic gains between locations, there is a need for caution because gains in North Carolina are expressed as an improvement in disease score (scale 0 to 5) over the population mean and gains in Florida are an improvement in reducing the probability of plant collapse (scale 0 to 1 ) over the population mean. Selection of the most resistant five full-sib families would increase genetic gains in disease resistance by 18.0 and $14.6 \%$ in the seedling test and clonal test, respectively, in North Carolina and by 28.9 and $29.1 \%$ in Florida; however, clonal testing and deployment of the best clone within each of these five families would increase genetic gains to $53.0 \%$ in North Carolina and $73.7 \%$ in Florida. The commercial deployment of full-sib families is not feasible because strawberry is a clonally propagated crop. However, predicted genetic gains obtained by selecting the best families are useful as a measure of progress in recurrent selection programs.

In conclusion, this study reveals large potential to increase resistance to plant collapse caused by $C$. gloeosporioides through recurrent selection and also through deploying clonal cultivars in specific locations. Selecting high-performing clones from the most resistant full-sib families is predicted to produce sizable genetic gains in resistance. Several superior clones from the most resistant families have been maintained for use in breeding at each location.

\section{ACKNOWLEDGMENTS}

We thank S. Gezan for a critical review of this manuscript and assistance with the analyses; and the research station staffs at the Horticultural Crops Research Station in Castle Hayne, NC and the Gulf Coast Research and Education Center in Wimauma, FL for their technical assistance.

\section{LITERATURE CITED}

1. Ballington, J. R., Shuman, J. L., Smith, B. J., Hokanson, S. C., and Gimenez, G. 2002. Breeding strawberries (Fragaria $\times$ ananassa) for resistance to anthracnose caused by Colletotrichum acutatum. Acta Hortic. 567:89-92.

2. Baltunis, B. S., Huber, D., White, T. L., Goldfarb, B., and Stelzer, H. E. 2007. Genetic gain from selection for rooting ability and early growth in vegetatively propagated clones of loblolly pine. Tree Genet. Genomes 3:227-238.

3. Burdon, R. D. 1977. Genetic correlation as a concept for studying genotype-environment interaction in forest tree breeding. Silv. Genet. 26:168-175.

4. Denoyes-Rothan, B., Guérin, G., Lercetau-Köhler, E., and Risser G. 2005. Inheritance of resistance to Colletotrichum acutatum in Fragaria $\times$ ananassa. Phytopathology 4:405-412.

5. Galletta, G. B., Smith, B. J., and Gupton, C. L. 1993. Strawberry parent clones US70, US159, US292 and US438 resistant to anthracnose crown rot. HortScience 28:1055-1056.

6. Gilmour, A. R., Gogel, B. J., Cullis, B. R., and Thompson, R. 2009. ASReml User Guide. Release 3.0. VSN International Ltd., Hemel Hempstead, HP1 1ES, UK. www.vsni.co.uk

7. Gimenez, G., and Ballington, J. R. 2002. Inheritance of resistance to Colletotrichum acutatum Simmonds on runners of garden strawberry and its backcrosses. HortScience 37:686-690.

8. Griffing, B. 1956. Concept of general and combining ability in relation to diallel crossing systems. Aust. J. Biol. Sci. 9:463-493.

9. Gupton, C. L., and Smith, B. J. 1991. Inheritance of resistance to Colletotrichum species in strawberry. J. Am. Soc. Hortic. Sci. 116:724-727.

10. Howard, C. M., Mass, J. L., Chandler, C. K., and Albregts, E. E. 1992. Anthracnose of strawberry caused by the Colletotrichum complex in Florida. Plant Dis. 76:976-981.

11. Lewers, K.S., Turechek, W. W., Hokanson, S. C., Maas, J. L., Hancock, J. F., Serçe, S., and Smith, B. J. 2007. Evaluation of elite native strawberry germplasm for resistance to anthracnose crown rot disease caused by Colletotrichum species. J. Am. Soc. Hortic. Sci. 132:842-849.

12. MacKenzie, S. J., Legard, D. E., Timmer, L. W., Chandler, C. K., and Peres, N. A. 2006. Resistance of strawberry cultivars to crown rot caused by Colletotrichum gloeosporioides isolates from Florida is nonspecific. 
Plant Dis. 90:1091-1097.

13. MacKenzie, S. J., Mertely, J. C., and Peres, N. A. 2009. Curative and protectant activity of fungicides for control of crown rot of strawberry caused by Colletotrichum gloeosporioides. Plant Dis. 93:815-820.

14. MacKenzie, S. J., Seijo, T. E., Legard, D. E., Timmer, L. W., and Peres, N. A. 2007. Selection for pathogenicity to strawberry in populations of Colletotrichum gloeosporioides from native plants. Phytopathology 97:1130-1140.

15. Mckeand, S. E., Li, B., Grissom, J. E., Isik, F., and Jayawickrama, J. S. 2006. Genetic parameter estimates for growth traits from diallel tests of loblolly pine throughout the southern United States. Silv. Genet. 57:101110.

16. Mrode, R. A. 1996. Linear Models for the Prediction of Animal Breeding Values. CAB International, Wallingford, UK.

17. Mullin, T. J., and Park, T. S. 1992. Estimating genetic gains from alternative breeding strategies for clonal forestry. Can. J. For. Res. 22:1423.

18. Smith, B. J. 2008. Epidemiology and pathology of strawberry anthracnose: A North American perspective. HortScience 43:69-73.

19. Smith, B. J., Gupton, C. L., Galletta, G. B., Maas, J. L., Enns, J. M., Ballington, J. R., Constantin, R. J., Divittorio, T. J., and Himelrick, D. 1998. 'Pelican' strawberry. HortScience 33:1082-1084.

20. Tempelman, R. J 1998. Generalized linear mixed models in dairy cattle breeding. J. Dairy Sci. 81:1428-1444.

21. Ureña-Padilla, A. R., MacKenzie, S. J., Bowen, B. W., and Legard, D. E. 2002. Etiology and population genetics of Colletotrichum spp. causing crown and fruit rot of strawberry. Phytopathology 92:1245-1252.

22. Xiao, C. L., MacKenzie, S. J., and Legard, D. E. 2004. Genetic and pathogenic analyses of Colletotrichum gloeosporioides isolates from strawberry and noncultivated hosts. Phytopathology 90:446-453. 